\title{
Homogeneous Microstructure of Bulk K4169 Superalloy Obtained by Stable Undercooling
}

\author{
Zhang Keren ${ }^{1,2}, \quad$ Xie Faqin $^{1}, \quad$ Hu Rui ${ }^{2}, \quad$ Li Jinshan ${ }^{2}, \quad$ Wu Xiangqing ${ }^{1}$ \\ ${ }^{I}$ School of Aeronautics, Northwestern Polytechnical University, Xi'an 710072, China; ${ }^{2}$ State Key Laboratory of Solidification Processing, \\ Northwestern Polytechnical University, Xi'an 710072, China
}

\begin{abstract}
By improving the method of $\mathrm{B}_{2} \mathrm{O}_{3}$ glass purification combined with cycle superheating based on traditional undercooling method, a stable undercooling above $200 \mathrm{~K}$ of $100 \mathrm{~g}$ bulk K4169 superalloy was obtained, and the largest undercooling went to 271 $\mathrm{K}$. The effects of purification and superheating temperature on undercooling have been discussed. Moreover, the three-dimensional numerical analysis of temperature field inside the undercooled melt has been presented, and the maximum temperature deviation in different parts is only $14 \mathrm{~K}$ before nucleation. In contrast with the as-solidified microstructure, the grain size will increase with the increment of nucleating temperature. Generally, the difference of microstructure in $100 \mathrm{~g}$ undercooled K4169 superalloy is tiny and the average grain size of the superalloy with $271 \mathrm{~K}$ undercooling is $12 \pm 2 \mu \mathrm{m}$.
\end{abstract}

Key words: K4169 superalloy; undercooling; purification; temperature field; microstructure; homogeneity

The microstructure of undercooled melt after rapid solidification is one of the most important fundamental subject in various materials ${ }^{[1-3]}$. The so-called undercooling refers to the phenomenon of pure liquid metal or alloy below a certain temperature range without crystallization or solidification. Molten glass purification combined with cycle superheating is one of the methods which can achieve reasonable undercooling successfully ${ }^{[4-6]}$.

To date, high undercooling in bulk alloys has been widely investigated ${ }^{[7,8]}$. Previous researches only focused on the relationship between superheating, holding time and undercooling. However, some details of the undercooling process have not been studied systematically yet, such as the replacement of purification and the way of cycle superheating, and thus the undercooling degree is obtained randomly. Furthermore, with the increase of melt size, the melt needs longer time to cool down and the external part cools faster than the center. So the inhomogeneous temperature field inside the undercooling melt leads to the forming of inhomogeneous microstructure ${ }^{[9]}$.
As one of the most widely used superalloys in modern industry, K4169 superalloy shows outstanding performance in elevated temperature environment, and it's widely used as the critical structural components in gas-turbine engines. Therefore, lots of investigations have been carried out for a better understanding on K4169 superalloy ${ }^{[10-13]}$ and the research of undercooled solidification of K4169 is indispensable. In the present work, the high undercooling of K4169 superalloy has been achieved by a method of replacement of molten glass combined with optimized cycle superheating. And the temperature field in the cooling process of large size melt was simulated to figure out the way how the temperature distribution affects the uniformity of microstructure.

\section{Experiment}

The undercooling experiment was conducted by a glass purification method in a high frequency induction unit with a coil mounted in atmosphere. The glass flux was $\mathrm{B}_{2} \mathrm{O}_{3}$ which was dehydrated at $1073 \mathrm{~K}$ for $5 \mathrm{~h}$ in advance. In each

Received date: February 18, 2015

Foundation item: National Basic Research Program of China (2011CB610404); Research Found of the State Key Laboratory of Solidification Processing China (62-TP-2011); "111" Project (B08040)

Corresponding author: Hu Rui, Ph. D., Professor, State Key Laboratory of Solidification Processing, Northwestern Polytechnical University, Xi'an 710072, P. R. China, Tel: 0086-29-88491764, E-mail: rhu@nwpu.edu.cn

Copyright ( 2 2016, Northwest Institute for Nonferrous Metal Research. Published by Elsevier BV. All rights reserved. 
experiment, a bulk K4169 superalloy of $100 \mathrm{~g}$ was placed in a quartz crucible of $20 \mathrm{~mm}$ diameter and covered with $\mathrm{B}_{2} \mathrm{O}_{3}$ powder on the top and the bottom. Then the crucible was placed in the coil of the high frequency induction unit. Firstly the sample was heated to $773 \sim 873 \mathrm{~K}$ until completely enwrapped by the molten $\mathrm{B}_{2} \mathrm{O}_{3}$. Then the temperature increased to 1821 1881 K which was 200 260 $\mathrm{K}$ above the liquidus temperature $\left(T_{\mathrm{L}}\right)$ and held for $3 \sim 5 \mathrm{~min}$. After that the temperature decreased to $T_{\mathrm{L}}+30 \mathrm{~K}$ and held for 3 5 min. The process was cycled $2 \sim 3$ times to generate different undercooling.

In each cycle, the negative pressure suction device was used to replace the molten $\mathrm{B}_{2} \mathrm{O}_{3}$, as illustrated in Fig.1. The device can extract molten $\mathrm{B}_{2} \mathrm{O}_{3}$ from the upper edge of the quartz crucible, following by addition of same amount of fresh $\mathrm{B}_{2} \mathrm{O}_{3}$. When the interface between alloy melt and $\mathrm{B}_{2} \mathrm{O}_{3}$ was stable and there were no air bubbles, it was time to stop heating. The thermal behaviors of samples were monitored by a double-color pyrometer with $\pm 5 \mathrm{~K}$ accuracy and $100 \mathrm{~ms}$ response time.

The solidified samples were cut along the longitudinal section, polished and etched using a solution of $10 \mathrm{~g} \mathrm{CuCl}_{2}$ $+100 \mathrm{~mL} \mathrm{HCl}+100 \mathrm{~mL}$ alcohol. The as-solidified microstructures of 5 parts on the longitudinal section were observed by Olympus PMG3 metallographic microscope $(\mathrm{OM})$, which are marked by a, b, c, d and e as shown in Fig.2. The $\mathrm{B}_{2} \mathrm{O}_{3}$ was analyzed by X-ray diffraction (XRD).

\section{Results and Discussion}

\subsection{Influencing factors of purification}

2.1.1 Influence of $\mathrm{B}_{2} \mathrm{O}_{3}$ on purification

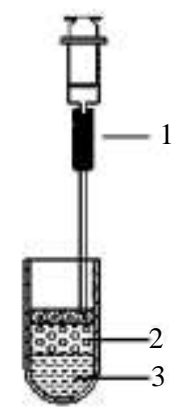

1-negative pressure suction device, 2-molten $\mathrm{B}_{2} \mathrm{O}_{3}, 3$-alloy melt

Fig.1 Principle diagram of negative pressure suction device

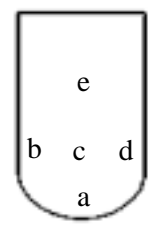

Fig.2 Longitudinal section of the superalloy
The selection of purification agent is very important for achieving high undercooling ${ }^{[14]}$. The reason why $\mathrm{B}_{2} \mathrm{O}_{3}$ is widely used can be ascribed to that the molten $\mathrm{B}_{2} \mathrm{O}_{3}$ in amorphous state won't provide heterogeneous nucleus, meanwhile the sticky molten $\mathrm{B}_{2} \mathrm{O}_{3}$ can eliminate heterogeneous nucleation particles through physical absorption, and it can also melt some impurities through chemical reaction to achieve physicochemical purification ${ }^{[15]}$ In addition, the molten $\mathrm{B}_{2} \mathrm{O}_{3}$ can not only protect the melt from atmosphere to avoid the formation of oxide film, but also work as a high-damping isolation layer to eliminate the interference from external vibration. However, the amorphous $\mathrm{B}_{2} \mathrm{O}_{3}$ will be crystallized at high temperature by absorbing large numbers of metal ions such as $\mathrm{Fe}^{2+}$ and $\mathrm{Fe}^{3+}$ in alloy melt, and the viscosity of molten $\mathrm{B}_{2} \mathrm{O}_{3}$ will be decreased. To some extent, the crystallization of $\mathrm{B}_{2} \mathrm{O}_{3}$ provides heterogeneous nucleuses which may lead to the large decrease of undercooling ${ }^{[16]}$. Fig.3 shows the XRD patterns of $\mathrm{B}_{2} \mathrm{O}_{3}$ after and before the undercooling experiment. It can be seen that a crystallization peak appears obviously in the used $\mathrm{B}_{2} \mathrm{O}_{3}$, however, in the unused $\mathrm{B}_{2} \mathrm{O}_{3}$ there appears a broad diffraction peak which is a typical symbol of amorphous state. It suggests that $\mathrm{B}_{2} \mathrm{O}_{3}$ will be seriously crystallized after participating the purification for a long time. Thus, it is not sufficient to add $\mathrm{B}_{2} \mathrm{O}_{3}$ in bulk alloys only once during the undercooling experiment and it is indispensable to replace the molten $\mathrm{B}_{2} \mathrm{O}_{3}$ by adopting the negative pressure suction device as shown in Fig.1.

\subsubsection{Influence of superheating on purification}

Normally it is difficult to get a desirable undercooling by superheating only once, and thus the method of cycle superheating is usually adopted, which means that the alloy is superheated for a few minutes and then cooled down till solidification in each cycle. Nevertheless, this kind of cycle superheating is not most suitable, due to the fact that the alloy will be segregated with $\mathrm{B}_{2} \mathrm{O}_{3}$ during solidification and exposed to the air during the process of reheating. In order to avoid the oxidation, the temperature of alloy melt should be cooled to $T_{\mathrm{L}}+30 \mathrm{~K}$ for $1 \sim 3 \mathrm{~min}$ and then reheated to

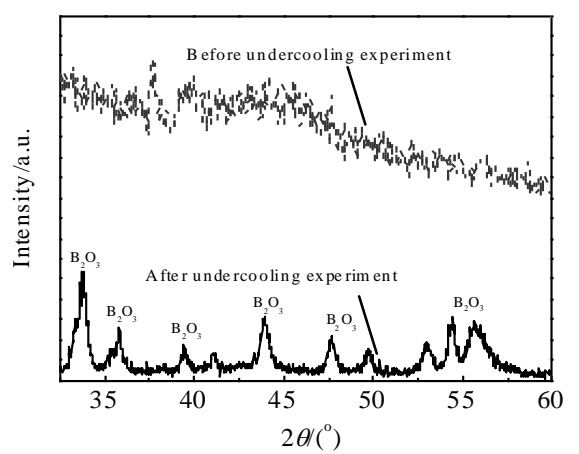

Fig.3 XRD patterns of $\mathrm{B}_{2} \mathrm{O}_{3}$ before and after undercooling experiment 
$T_{\mathrm{L}}+200 \sim 260 \mathrm{~K}$ for $1 \sim 3 \mathrm{~min}$. At the same time, the interface between the alloy melt and $\mathrm{B}_{2} \mathrm{O}_{3}$ can be changed by temperature. When the temperature is high, the alloy melt shows a shape of sharp elliptic ball on the top; on the other hand when the temperature is low, the alloy melt shows a shape of flat ball which can be completely covered by the molten $\mathrm{B}_{2} \mathrm{O}_{3}$. In this procedure, the alloy melt will make full attachment with molten $\mathrm{B}_{2} \mathrm{O}_{3}$ and the cohesive adsorption will be achieved sufficiently. Meanwhile the impurities dissolved and adsorbed in the molten $\mathrm{B}_{2} \mathrm{O}_{3}$ will be rejected far away from the interface, so that the content of impurities is greatly reduced near the interface. Eventually high undercooling can be obtained by this optimized cycle superheating method.

Thus the replacement of molten glass combined with optimized cycle superheating method (the optimized method) can obtain a stable and high undercooling. Previous reports confirmed that the solidification of the undercooled melts was initiated by heterogeneous nucleation ${ }^{[17,18]}$. The nucleation particles always appeared in the interface of purified alloy and molten glass. The heterogeneous nucleation rate $J_{\mathrm{a}}$ in the melt surface can be expressed as ${ }^{[19]}$ :

$$
J_{\mathrm{a}}=10^{21} \xi \varphi_{0} \eta^{-1} \exp \left[-\Delta G^{*} f(\theta)(k T)^{-1}\right]
$$

where $\xi$ refers to the activating factor, $\varphi_{0}$ the area fraction of heterogeneous nucleation particle, $\eta$ the viscosity of liquid metal or alloy, $\Delta G^{*}$ the nucleation activation energy, $f(\theta)$ the heterogeneous nucleation factor, and $k$ the Boltzmann constant. When the system is confirmed as K4169 superalloy, $f(\theta)$ is mainly determined by the oxides of $\mathrm{Ni}, \mathrm{Fe}$ and $\mathrm{Cr}$. Thus $k, \eta$ and $f(\theta)$ are all constants, and $J_{\mathrm{a}}$ is just related with $\xi, \varphi_{0}$ and $\Delta G^{*}$. The optimized method will improve the passivation effect of the heterogeneous nucleation particle (i.e. reduce $\xi$ ), accelerate the dissolution of oxide substrate in the replacement of molten $\mathrm{B}_{2} \mathrm{O}_{3}$ (i.e. reduce $\varphi_{0}$ ), and increase the cluster size to promote the melt homogenization of structure and composition (i.e. increase $\Delta G^{*}$ ). Thus the heterogeneous nucleation rate $J_{\mathrm{a}}$ can be decreased.

The optimized method and the traditional superheating method are both adopted in a series of undercooling experiments for bulk K4169 superalloy. Compared with the optimized method, the traditional superheating method is an undercooling process which has fixed superheating temperature, holding time and it always cools till solidification in each cycle ${ }^{[5,7,20]}$. The distributions of undercooling under different superheating are shown in Fig.4, in which gray scatters are from the optimized method and the black scatters are from the traditional method. It can be noticed that the distribution of undercooling in the traditional method is very fragmented and random, even under the same degree of superheating, the undercooling is still different, and it presents a rising trend with the increase of superheating. On the other hand, the distribution of undercooling in the optimized method is so stable that the undercooling always stays above $200 \mathrm{~K}$, even if the superheating is only $130 \mathrm{~K}$. The largest undercooling is $271 \mathrm{~K}$.

\subsection{Microstructure of bulk undercooled K4169 superalloy}

In the traditional researches of undercooling, the melt usually cools down from high superheating temperature $\left(T_{\mathrm{L}}+\right.$ $200 \sim 260 \mathrm{~K}$ ) directly to get a large dynamics undercooling. Under this condition, the size of a sample is small and the thermal dissipation is homogeneous. Thus it's feasible for small sample to get a high undercooling ${ }^{[21,22]}$. However, with the increase of the sample size, it's more difficult to obtain a stable high undercooling $(>200 \mathrm{~K})$ and homogeneous microstructure. This is because the surface of the melt is cooled faster than the center which will result in a large temperature gradient when the melt cools from high superheating $\left(T_{\mathrm{L}}+200 \sim 260 \mathrm{~K}\right)$ directly. In order to make the solidified microstructure more homogeneous in bulk alloy, the cooling temperature is supposed to be as low as possible, meanwhile the nucleation should also be forbidden. As aforementioned, a stable high undercooling can be achieved easily upon choosing an appropriate purification method even in low superheating temperature. Based on this, the high superheated melt can be cooled to $T_{\mathrm{L}}+30 \mathrm{~K}$ for $2 \sim 5 \mathrm{~min}$ after all cycle superheating processes to reduce the cooling time dramatically, and then a more homogeneous microstructure can be obtained theoretically.

For the quantitative discussion, the temperature-time

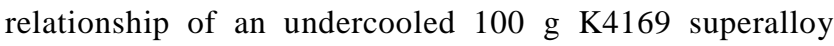
during the solidification was measured by infrared thermometer (as shown in Fig.5), and $T_{\mathrm{N}}$ is the nucleation temperature. The temperature was only measured at point $b$ in Fig.2. The curve has no solidification platform and the whole solidification process finished in rapid recalescence. However, many other parts of temperature especially in the center could not be measured by the infrared thermometer, and the information obtained from the curve is too rare to analyze the whole undercooled alloy. Under this condition, ANSYS software was adopted to simulate the temperature field of the whole

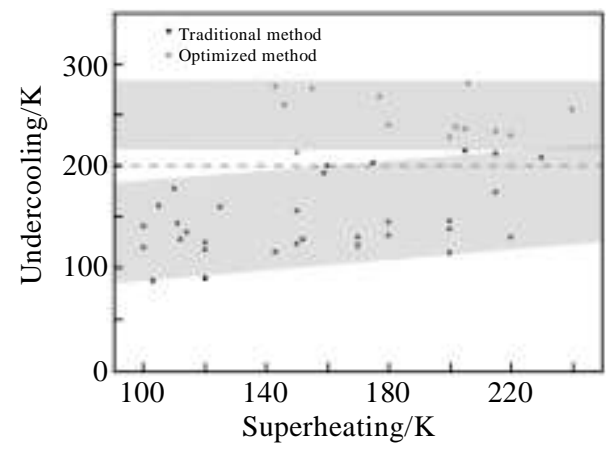

Fig.4 Distribution of undercooling in different superheating obtained from the traditional method and the optimized method 
melt which was cooled from $T_{\mathrm{L}}+30 \mathrm{~K}$ to the nucleation temperature $T_{\mathrm{N}}$, so it can shed light on the way how temperature field influences its microstructure. The parameters of considered undercooled melt are shown in Table 1 and the boundary conditions are considered as the thermal radiation and convection ${ }^{[23]}$.

From the simulation result presented in Fig.6, one can notice that the maximum temperature deviation in different parts is only $14 \mathrm{~K}$, as well as the highest temperature in the center (Fig.6e) and lowest in the upper (Fig.6g). In different cross sections, the temperature deviation between the center and the surface is also different. The deviation is only $4 \mathrm{~K}$ in the middle (Fig.6e, 6f) and bottom (Fig.6c, 6b), as well as 8 $\mathrm{K}$ in the upper (Fig.6h, 6g). In generally, there is only tiny difference in the distribution of temperature at nucleation temperature. In the size of K4169 superalloy, the temperature is homogeneous in the melt which is about to nucleate.

In order to understand the relationship between the microstructure and temperature field, the microstructures in different parts were observed. As shown in Fig.7, there are five microstructures of different parts on a, b, c, d and e in Fig.2 for $271 \mathrm{~K}$ undercooling K4169 superalloy. By calculating, the grain sizes are (a) $10.9 \mu \mathrm{m}$, (b) $11.5 \mu \mathrm{m}$, (c) $12 \mu \mathrm{m}$, (d) $11.5 \mu \mathrm{m}$ and (e) $14 \mu \mathrm{m}$. It can be found that the microstructures are nearly homogenous, which only have tiny difference, and the average grain size is about $12 \pm 2 \mu \mathrm{m}$. To compare the temperature and the microstructure of each point, the temperature of point $\mathrm{e}$ is the highest and point a is the lowest. Based on this temperature distribution point e has the largest grain size $(14 \mu \mathrm{m})$ and point a has the smallest grain size $(10.9 \mu \mathrm{m})$. Besides this, points $b$ and $d$ have the same grain size due to the equal nucleating temperature 1350

Table 1 Parameters of considered undercooled melt

\begin{tabular}{ccccc}
\hline$\left(T_{\mathrm{L}}+30 \mathrm{~K}\right) / \mathrm{K}$ & $t_{\mathrm{c}} / \mathrm{s}$ & $\delta / \mathrm{mm}$ & $d / \mathrm{mm}$ & $h / \mathrm{mm}$ \\
\hline 1651 & 55 & 3 & 20 & 40 \\
\hline
\end{tabular}

Note: $\left(T_{\mathrm{L}}+30 \mathrm{~K}\right)$-initial temperature, $t_{\mathrm{c}}$-cooling time, $\delta$-wall thickness of quartz crucible, $d$-inside diameter of quartz crucible, $h$-height of K4169 superalloy

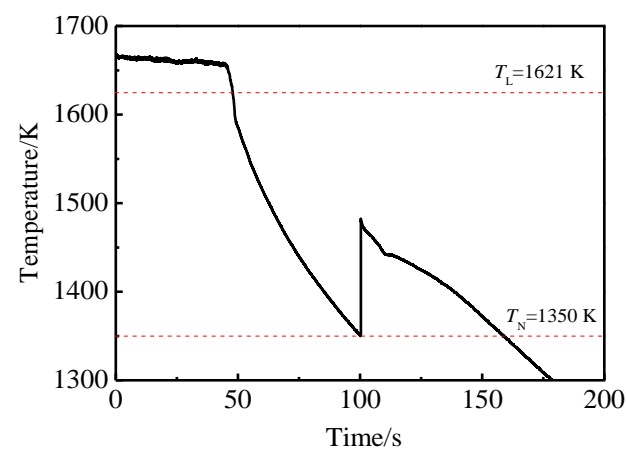

Fig.5 Temperature-time relationship of an undercooled $100 \mathrm{~g}$ K4169 superalloy

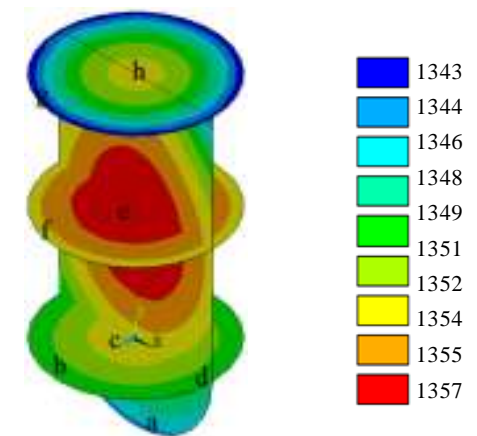

Fig.6 Three-dimensional temperature distribution of K4169 superalloy melt at nucleation temperature

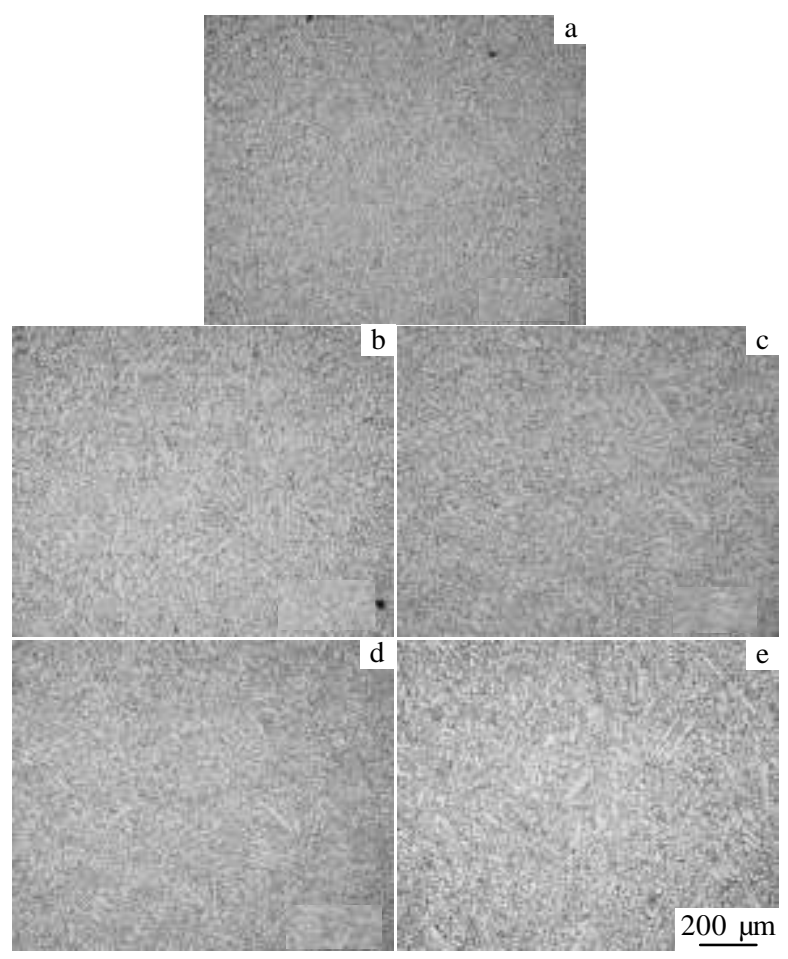

Fig.7 Microstructures of different points in Fig.2 for K4169 superalloy

K. It can be concluded that the grain size increases with increasing of nucleating temperature. Based on the classical nucleation theory ${ }^{[24]}$, the lower the nucleation temperature is, the higher undercooling can be obtained, which increases the nucleation rate in the undercooled melt. As soon as the nucleation activates from nucleus, the dendrite will grow rapidly and radically. Meanwhile, the dendrite tip radius will decrease with increasing of undercooling ${ }^{[25]}$. For the effect of remelting and the inter stress from melt shrinkage on solidification dendrite, the dendrite with different sizes can be distorted and fragmented into granular grain.

By integrating the work we have done, the experimental results are in good agreement with the simulation of temperature field: uniform temperature field will lead to a 
uniform microstructure; conversely, different nucleating temperatures will generate different microstructures. So the experimental results can provide theory support for further research on high undercooling of bulk alloys.

\section{Conclusions}

1) The molten $\mathrm{B}_{2} \mathrm{O}_{3}$ should be renewed by the negative pressure suction device during the process of cycle superheating to avoid crystallization.

2) The replacement of molten glass combined with optimized cycle superheating method is adopted in the undercooling experiment for $100 \mathrm{~g} \mathrm{~K} 4169$ superalloy, a stable undercooling above $200 \mathrm{~K}$ is obtained and the highest undercooling goes to $271 \mathrm{~K}$.

3) The three-dimensional distribution of temperature field from $T_{\mathrm{L}}+30 \mathrm{~K}(1651 \mathrm{~K})$ cooling to $T_{\mathrm{N}}(1350 \mathrm{~K})$ can be simulated by ANSYS software. The maximum temperature deviation in different parts is only $14 \mathrm{~K}$. In contrast with the solidification microstructure, the grain size will increase with the increment of nucleating temperature. But the difference in microstructure is tiny and the average grain size is $12 \pm 2 \mu \mathrm{m}$.

\section{References}

1 Lu Yiping, Lin Xin, Yang Gencang et al. Journal of Applied Physics[J], 2008, 104(1): 013535

2 Luo S B, Wang W L, Chang J et al. Acta Materialia[J], 2014, 69: 355

3 Clopet C R, Cochrane R F, Mullis A M. Acta Materialia[J], 2013, 61: 6894

4 Wang Pei, Liu Feng, Li Zhengxian. Rare Metal Materials and Engineering [J], 2010, 39(1): 482 (in Chinese)

5 Wilde G, Sebright J L, Perepezko J H. Acta Materialia[J], 2006, 54: 4759

6 Yang C L, Yang G C, Liu F et al. Rare Metal Materials and Engineering[J], 2009, 38(10): 1745 (in Chinese)
7 Xi Zengzhe. Thesis for Doctorate[D], Xi'an: Northwestern Polytechnical University, 1998: 27 (in Chinese)

8 Li Jinfu, Zhou Yaohe. J Mater Sci [J], 2000, 35: 5581

9 Li Delin, Yang Gencang, Zhou Yaohe. Trans Nonferrous Met Soc China[J], 1994, 4(1): 64

10 Li Xianghui, Zhang Yong, Hou Xueqin et al. Rare Metal Materails and Engineering[J], 2014, 43(1): 199 (in Chinese)

11 Arrazola P J, Kortabarria A, Madariaga A et al. Simulation Modelling Practice and Theory[J], 2014, 41: 87

12 Cheng L, Xue X, Tang B et al. Materials Science and Engineering $A[\mathrm{~J}], 2014,606: 24$

13 Parimi L L, Clark D, Attallah M M. Materials Characterization [J], 2014, 89: 102

14 Zhou Shengyin. Thesis for Doctorate[D], Xi'an: Northwestern Polytechnical University, 2013: 35 (in Chinese)

15 Wei Bingbo. Thesis for Doctorate [D], Xi' an: Northwestern Polytechnical University, 1989: 31 (in Chinese)

16 Yang Changlin, Yang Gencang, Liu Feng et al. Acta Metallurgica Sinica[J], 2008, 44(8): 956 (in Chinese)

17 Li J Z, Liu J, Zhang M X et al. J Alloy Compd[J], 2010, 499: 39

18 Han X J, Yang C, Yang G C et al. Material Science and Engineering $A[\mathrm{~J}], 2001,307: 35$

19 Jacobson L A, McKittrich J et al. Material Science and Engineering $R[\mathrm{~J}], 1994, \mathrm{R} 11: 355$

20 Zhou Jiankun, Li Jianguo. J Alloy Compd[J], 2008, 461: 113

21 Yang Changlin, Liu Feng, Yang Gencang et al. Journal of Crystal Growth[J], 2009, 311: 404

22 Chen Y Z, Liu F, Yang G C et al. J Alloy Compd[J], 2007, 427(16): L1

23 Liu Tao, Yang Fengpeng. Mastering ANSYS[M]. Beijing: Tsinghua University Press, 2002: 345 (in Chinese)

24 Turnbull D J. Journal of Chemical Physics [J], 1981, 18: 950.

25 Liu Feng, Guo Xuefeng, Yang Gencang. Materials Research Bulletin[J], 2001, 36: 181

\title{
大体积 K4169 高温合金深过冷及其组织均匀性的研究
}

\author{
张可人 ${ }^{1,2}$, 谢发勤 ${ }^{1}$, 胡 锐 $^{2}$, 李金山 ${ }^{2}$, 吴向清 ${ }^{1}$ \\ (1. 西北工业大学航空学院, 陕西 西安 710072) \\ (2. 西北工业大学 凝固技术国家重点实验室, 陕西 西安 710072)
}

\begin{abstract}
摘 要: 在传统深过冷工艺的基础上, 通过对传统工艺中 $\mathrm{B}_{2} \mathrm{O}_{3}$ 玻璃净化法和循环过热方法的改进, 可使较大体积 $\mathrm{K} 4169$ 高温合金稳定地 获得 $200 \mathrm{~K}$ 以上过冷度，其中 $100 \mathrm{~g}$ 合金熔体的最大过冷度达 $271 \mathrm{~K}$ 。采用ANSYS软件模拟了 $100 \mathrm{~g} \mathrm{~K} 4169$ 高温合金冷却过程中熔体温度场 的分布, 熔体形核前最大温差仅为 $14 \mathrm{~K}$ 。在此基础上观察合金不同部位的凝固组织, 发现组织随着形核温度的升高而增大。总体来看组 织只有微小差别, 其平均晶粒尺寸为 $12 \pm 2 \mu \mathrm{m}$, 与模拟结果相吻合。

关键词：K4169高温合金; 深过冷; 净化机制; 温度场; 组织均匀
\end{abstract}

作者简介: 张可人, 女, 1990 年生, 硕士生, 西北工业大学航空学院, 陕西 西安 710072, 电话: 029-88491764, E-mail: 542821948@qq.com 